\title{
Factors associated with therapy noncompliance in type-2 diabetes patients
}

\author{
Lizbeth Hernández-Ronquillo, MD,(1) José Francisco Téllez-Zenteno, MSc, ${ }^{(2)}$ \\ Juan Garduño-Espinosa, MSc, ${ }^{(3)}$ Erick González-Acevez, MD. ${ }^{(3)}$
}

\begin{abstract}
Hernández-Ronquillo L, Téllez-Zenteno JF, Garduño-Espinoza J, González-Acevez E. Factors associated with therapy noncompliance in type-2 diabetes patients. Salud Publica Mex 2003;45:191-197.

The English version of this paper is available too at: http://www.insp.mx/salud/index.html
\end{abstract}

\begin{abstract}
Objective. To identify the frequency and factors associated with therapy noncompliance in type-2 diabetes mellitus patients. Material and Methods. A cross-sectional study was carried out in 79 patients with type-2 diabetes mellitus seen in major hospitals of Mexico City. Patients were visited at home, from March 1998 to August 1999, to measure compliance with prescribed therapy. Complying patients were defined as those taking at least $80 \%$ of their pills or $80 \%$ of their corresponding insulin dose.The degree of compliance with therapy components (diet, amount of exercise, and keeping appointments) was measured. Results. The average age of study subjects was 59 years (SD II years); 73\% $(n=58)$ were female subjects. The overall frequency of noncompliance was $39 \%$. Noncompliance rates were: $62 \%$ for dietary recommendations, $85 \%$ for exercise, $17 \%$ for intake of oral hypoglycemic medication, 13\% for insulin application, and $3 \%$ for appointment keeping. Hypertension plus obesity was the only factor significantly associated with noncompliance (OR 4.58, CI 95\% I.0, 22.4, p=0.02). Conclusions. The frequency of therapy noncompliance was very high, especially for diet and exercise. The English version of this paper is available too at: http://www.insp.mx/salud/ index.html
\end{abstract}

Key words: diabetes mellitus, non-insulin-dependent; noncompliance; diabetic diet; exercise; depression; Mexico
Hernández-Ronquillo L, Téllez-Zenteno JF, Garduño-Espinoza J, González-Acevez E.

Frecuencia y factores asociados al incumplimiento terapéutico en pacientes con diabetes mellitus tipo 2 . Salud Publica Mex 2003;45:191-197.

El texto completo en inglés de este artículo también está disponible en: http://www.insp.mx/salud/index.html

\section{Resumen}

Objetivo. Identificar la frecuencia y factores asociados al incumplimiento terapéutico en pacientes con diabetes mellitus tipo 2. Material y métodos. Se llevó a cabo un estudio transversal en cuatro clínicas y hospitales de la Ciudad de México, en 79 pacientes con diabetes mellitus tipo 2. Se recolectaron datos sobre el cumplimiento terapéutico, para lo cual se visitó el domicilio de los sujetos de estudio entre marzo de 1998 y agosto de 1999, con el fin de contar los medicamentos. Se definió cumplimiento cuando el paciente administró correctamente $80 \%$ de las pastillas o de la dosis de insulina que le correspondía. Se midió el grado de cumplimiento para cada una de las medidas terapéuticas (dieta, ejercicio y asistencia a citas). Resultados. La edad promedio del grupo fue de 59 años (DE= I I años); 58 pacientes $(73 \%)$ fueron del sexo femenino. La frecuencia de incumplimiento global fue de $39 \%$. La frecuencia de incumplimiento en el grupo donde se pudo llevar a cabo el conteo de medicamentos fue $62 \%$ para la dieta, $85 \%$ para el ejercicio, $17 \%$ para la administración de hipoglucemiantes, $13 \%$ para la aplicación de insulina y $3 \%$ para la asistencia a citas. Sólo la asociación de incumplimiento con la presencia de hipertensión arterial sistémica más obesidad fue estadísticamente significativa $(\mathrm{RM}=4.58, \mathrm{IC} 95 \%=1.0-22.4, p=$ 0.02 ). Conclusiones. La frecuencia de incumplimiento fue muy alta, especialmente en lo que se refiere a la dieta y al ejercicio. El texto completo en inglés de este artículo también está disponible en: http://www.insp.mx/salud/index.html

Palabras clave: diabetes mellitus no insulino-dependiente; incumplimiento; dieta para diabéticos; ejercicio; depresión; México

This work was partially supported by Fundación UNAM.

(I) Instituto Nacional de Perinatología. México, DF, México.

(2) Instituto Nacional de Ciencias Médicas y Nutrición Salvador Zubirán. Grupo AFINES, Facultad de Medicina, Universidad Nacional Autónoma de México, México, DF, México.

(3) Instituto Mexicano del Seguro Social, México, DF, México.

Received on: May 21, 2002 - Accepted on: January 10,2003

Address reprint requests to: Dr. José Francisco Téllez Zenteno. Departamento de Neurología. Instituto Nacional de Ciencias Médicas y de la Nutrición Salvador Zubirán. Vasco de Quiroga No. 15, colonia sección XVI,Tlalpan, I4000 México, DF. E-mail: liztellez@correo.unam.mx. 
$\mathrm{T}$ herapeutic compliance is defined as adherence of the patient to therapy indications prescribed by the attending physician. Noncompliance may consist of not initiating therapy, finishing therapy and not beginning it again if necessary, or following indications incorrectly. There may be errors of omission, dose, schedule, or failure to follow medical indications. Following instructions given by other people or self-regulation of medication are also considered errors. ${ }^{1}$

Compliance has been assessed by measuring the amount of medication or its by-products through blood or urinary levels, and even with the use of radioactive material for tracing the frequency of use of prescribed medication. ${ }^{2,3}$

Diabetes mellitus (DM) is a condition that requires therapeutic control generally involving strict, rigorous, and permanent lifestyle changes. Diabetes control measures include dietary restrictions, physical activity, strict medication regimes, periodic medical control, and permanent metabolic control through laboratory studies. ${ }^{4}$

In type-2 diabetes mellitus, as in other chronic diseases, non-medical indications (diet, exercise, and periodic medical monitoring) have a fundamental importance. Thus, it is necessary to evaluate not only pharmacological compliance but also the correct observance of non-medical indications. The prevalence of therapy noncompliance in DM type- 2 has not been clearly established. The reported frequencies vary between $25 \%$ and $90 \%$, depending on the population and the therapeutic program examined., 5

The difference in the frequencies of therapy noncompliance reported in previous studies seems to be due not only to disparity of diagnostic criteria or measurement instruments, but also to secondary variations like cultural factors, family characteristics, or social organization of the studied groups. For example, Morrison $^{7}$ found that adult Jamaican diabetic patients did not follow the therapy regime unless they developed serious complications, or they resumed their medication only a few days before their medical visit.

Complexity of treatment, barriers to access, a negative social environment, and the degree to which the patient's everyday life is affected, especially in chronic diseases like diabetes, have been described among the factors associated with noncompliance. ${ }^{8,9}$

The objective of this study was to determine the frequency of therapy noncompliance in a sample of Mexican patients with type- 2 diabetes mellitus. Also, some risk factors potentially associated with therapy noncompliance were explored.

\section{Material and Methods}

A cross-sectional study was carried out in 79 patients with type-2 diabetes mellitus in four clinics of Mexico City: Mexican Institute of Social Security' San Pedro de los Pinos Clinic and Siglo XXI National Medical Center (Clínica San Pedro de los Pinos y Centro Médico Nacional Siglo XXI, del Instituto Mexicano del Seguro Social -IMSS-), and Ministry of Health Gea González Hospital and Margarita Chorné Health Center (Hospital Gea González y Centro de Salud Margarita Chorné, de la Secretaría de Salud -SSA-). Consecutive sampling was used. The sample population was followed throughout the duration of the study, from March 1998, to August 1999. Patients with type-2 diabetes mellitus who accepted to participate in the study (which required visiting them at home) were included. Diabetes mellitus diagnosis was performed following World Health Organization (WHO) criteria. ${ }^{10}$ Participants' records were reviewed to obtain data on diagnostic criteria, diabetes evolution time, therapy, appointment keeping, and comorbidity. Patients were asked to provide sociodemographic data. The Beck scale was used to measure depression. Furthermore, their medical prescriptions were reviewed to count the medication in their homes. Patients were visited at home seven days after the initial appointment. Interviews were conducted to explore therapeutic compliance with different methods (diet, exercise, medication) as well as obstacles to healthcare access. Study personnel checked dietary indication observance in the patient's home and counted medications.

Seventy-nine patients were studied; medication was counted in 58 of the patients at home ( $73 \%)$. Medication counting could not be performed for 21 patients (27\%) because no initial prescription was available, or because the patients were controlled only by means of diet and exercise.

Therapeutic compliance was measured in two ways: 1) when the counting of medication could be done, the percentage of missing tablets or insulin units was calculated. In these patients medication counting was considered to be $100 \%$ of their score; and 2) in patients whose medication could not be counted (because some patients did not keep what remained of the medication or because they were only prescribed a specific diet) compliance was evaluated in different ways (diet, exercise, appointment keeping, and medication) with an instrument to assess the patient's own estimation of his or her compliance. Compliance with diet, exercise, and medication was graded on a scale 
from zero to ten. The average score for these items represented the final grade of degree of compliance. The required amount for a patient to be considered compliant was $80 \%$, a figure that has been used in other studies. $^{8}$

The data collection instrument was validated in terms of appearance and content validity. In the first stage, 25 endocrinologists and 30 medical interns evaluated its contents for completeness and clarity. The grading system recommended by the specialists was a scale from 1 to 10 , since it was considered to be easier for patients to understand and it had been used in previous studies. Finally, the instrument was validated in terms of appearance and applied in the first stage to diabetic patients, to correct any unclear questions.

Depression was evaluated using the Beck depression inventory (BDI). The BDI is an instrument that has been extensively used over many years. It consists of 21 self-administered items that measure affective, cognitive, and somatic symptoms of depression. Each item evaluates a category according to a scale of 4 possible responses of increasing severity (except for items 14 and 20 which have only 3 options). The result is measured using a score between 0 and 61 . The cutoff points to identify people at risk for depression vary from scores of 14 to 17 points, according to different reports. For the present study, the limit of 14 points was used as cutoff. This cutoff point has been used in similar research studies on this topic. ${ }^{11,12}$ A sensitivity of $92 \%$ and a specificity of $77 \%$ have been documented with this diagnostic cutoff point. The categories measured were: 1) sadness, 2) pessimism, 3) sense of failure, 4) dissatisfaction, 5) sense of guilt, 6) sense of punishment, 7) self-disappointment, 8) self-criticism, 9) suicidal ideas, 10) tendency to cry, 11) irritability, 12) isolation, 13) indecisiveness, 14) concerns about appearance, 15) effort required to do things, 16) trouble sleeping, 17) sense of tiredness, 18) lack of appetite, 19) weight loss, 20) concern about health, and 21) decreased interest in sex.

Associations were assessed between therapy noncompliance and the following factors: 1) patients' comorbid characteristics, like depression and arterial hypertension; 2) sociodemographic aspects such as gender, civil status, religion, education, occupation, and family support; 3) characteristics of the disease such as evolution time and complications, and 4) level of medical care.

The data collection instrument included 137 items structured as follows: 1) identification data sheet; 2) personal data and prescription details; 3 ) socioeconomic level; 4) obstacles to healthcare access; 5) therapeutic compliance with medication, diet, exercise, and appointment keeping; 6) family support; 7) counting medication and reviewing dietary instructions, and 8) depression. Socioeconomic level was measured using a validated scale ${ }^{13}$ and depression was evaluated by the Beck depression inventory (BDI). ${ }^{14}$

For statistical analysis, descriptive statistics were obtained according to type of variable. Odds ratios with $95 \%$ confidence intervals were estimated. The statistical significance of associations was evaluated with the chi-squared test or with Fisher's exact test. The level of statistical significance was set at 0.05 for the twosided null hypothesis.

\section{Results}

The average age of the group was 59 (33-88) years $(\mathrm{SD}=11$ years); $73 \%(n=58)$ were women, $82 \%(n=65)$ had an educational level less than or equal to elementary school, $56 \%$ ( $n=44)$ were housewives, $73 \%$ $(n=58)$ had a good socioeconomic level. Sixty-seven percent $(n=53)$ were controlled with hypoglycemic drugs, diet and exercise; $20 \%(n=16)$ with insulin, diet and exercise, and $13 \%(n=10)$ with diet and exercise. The frequency of depression was $46 \%$ (36 patients), 48 were IMSS patients $(61 \%)$ and $31(39 \%)$ were SSA patients. IMSS patients receive medication at no cost, whereas in SSA institutions some may be given at no cost and some may have to be bought (Table I).

The overall noncompliance was $42 \%$ ( $n=33)$. Noncompliance in the group of 58 patients for whom medication was counted was $41 \%(n=24)$. The frequency of noncompliance in the group of 21 patients whose medication was not counted (because there was no initial prescription or the patients were only controlled by a diet) was $43 \%(n=9)$ (Table II). A comparative analysis was performed between these two groups. No statistically significant differences were found between sociodemographic characteristics and DM characteristics, and frequency of noncompliance. The only difference found was for type of therapy, given that 8 out of the 21 patients in whom the counting of medication could not be carried out were only controlled with a diet and did not take any medication; also, in the group in which the counting of medication was performed, everyone used insulin or hypoglycemic drugs.

The frequency of dietary noncompliance was $62 \%$ (49 patients), $85 \%$ for exercise (67 patients), $17 \%$ for intake of hypoglycemic drugs ( 9 patients out of 53 who had been prescribed hypoglycemic drugs), 13\% for insulin application (2 patients out of 16 who had been indicated treatment with insulin), and 3\% for appointment keeping ( 2 patients out of 79 ) (Table III). Only 38 
Table I

Demographic and CLINICAL CHARACTERISTICS OF Study subJects. MeXico City, I998-1999

\begin{tabular}{|c|c|c|c|c|c|c|}
\hline & $\begin{array}{c}\text { Com } \\
(n=\end{array}$ & & & $\begin{array}{l}\text { n- } \\
\text { liant } \\
\text { 33) }\end{array}$ & & tal \\
\hline & $f$ & $\%$ & $f$ & $\%$ & $f$ & $\%$ \\
\hline Age & & & & & & \\
\hline$<60$ years old & 24 & 52 & 15 & 45 & 39 & 49 \\
\hline$\geq 60$ years old & 22 & 48 & 18 & 55 & 40 & 51 \\
\hline Gender & & & & & & \\
\hline Female & 34 & 74 & 24 & 73 & 58 & 73 \\
\hline Male & 12 & 26 & 9 & 27 & 21 & 27 \\
\hline Religion & & & & & & \\
\hline Catholic & 45 & 98 & 30 & 91 & 75 & 95 \\
\hline Other & I & 2 & 3 & 9 & 4 & 5 \\
\hline Education & & & & & & \\
\hline None & 7 & 15 & 9 & 27 & 16 & 20 \\
\hline Elementary school completed & 31 & 68 & 18 & 55 & 49 & 62 \\
\hline Secondary school or higher & 8 & 17 & 6 & 18 & 14 & 18 \\
\hline Civil status & & & & & & \\
\hline Single & 2 & 4 & 2 & 6 & 4 & 5 \\
\hline Married & 25 & 54 & 19 & 58 & 44 & 56 \\
\hline Widowed & II & 24 & II & 33 & 22 & 28 \\
\hline Divorced or living with someone & 8 & 17 & $\mathrm{I}$ & 3 & 9 & 11 \\
\hline Social-economic level & & & & & & \\
\hline High & 34 & 74 & 24 & 73 & 58 & 73 \\
\hline Medium & II & 24 & 8 & 24 & 19 & 24 \\
\hline Low & 1 & 2 & I & 3 & 2 & 3 \\
\hline Occupation & & & & & & \\
\hline Home & 23 & 50 & 21 & 64 & 44 & 56 \\
\hline Other & 23 & 50 & 12 & 36 & 35 & 44 \\
\hline Institution & & & & & & \\
\hline SSA & 19 & 41 & 12 & 36 & 31 & 39 \\
\hline IMSS & 27 & 59 & 21 & 64 & 48 & 61 \\
\hline Years from diagnosis & & & & & & \\
\hline$\geq 10$ years & 39 & 85 & 31 & 94 & 70 & 89 \\
\hline$<10$ years & 7 & 15 & 2 & 6 & 9 & II \\
\hline Glycemia average value & & & & & & \\
\hline$<200$ & 34 & 74 & 17 & 52 & 51 & 65 \\
\hline$\geq 200$ & 12 & 26 & 16 & 48 & 28 & 35 \\
\hline Medical unit & & & & & & \\
\hline MISS San Pedro de los Pinos Clinic & 24 & 52 & 18 & 55 & 42 & 53 \\
\hline Margarita Chorne Medical Center & 4 & 9 & 3 & 9 & 7 & 9 \\
\hline Gea González Hospital & 15 & 32 & 9 & 27 & 24 & 30 \\
\hline MISS century XXI National & & & & & & \\
\hline Medical Center & 3 & 7 & 3 & 9 & 6 & 8 \\
\hline Depression & & & & & & \\
\hline Yes & 18 & 39 & 18 & 55 & 36 & 46 \\
\hline No & 28 & 61 & 15 & 45 & 43 & 54 \\
\hline Complications of diabetes mellitus & & & & & & \\
\hline Yes & 16 & 35 & 20 & 60 & 36 & 46 \\
\hline No & 30 & 65 & 13 & 39 & 43 & 54 \\
\hline
\end{tabular}

patients (48\%) had a dietary prescription in their home. The frequency of noncompliance for IMSS patients was $64 \%(n=21)$ and $36 \%(n=12)$ for SSA patients (Table I).

The only factor associated with therapy noncompliance was the presence of comorbidity specifically related to hypertension and obesity (OR 4.58, 95\% CI $1.0,22.4, p=0.02)$. With regard to non-medical indications, 29 patients $(87 \%)$, referred that they could not follow the diet adequately due to the difficulty of changing previous habits (also because they had cramps, they were hungry, the food was not the same as they were used to eating before, etc.). Another reason for noncompliance was economical reasons $(n=10,30 \%)$. Regarding exercise, 9 patients $(27 \%)$ preferred not to do it because of associated diseases (especially arthritis); 15 patients did not exercise because of lack of time $(45 \%)$, and 9 patients $(27 \%)$ because of motivational and cultural causes (lack of motivation, idiosyncrasy, and change in their habits). With respect to medication, 7 out of the 53 patients $(13 \%)$ who were controlled with hypoglycemic drugs referred that they did not take them because they left their houses without taking their medication along and $13(25 \%)$ because of other causes (mainly forgetfulness). Regarding insulin application ( $n=16$ patients), $2(13 \%)$ of them referred that the reasons for noncompliance were that they had forgotten to administer it or that they were feeling well, and $2(13 \%)$ referred that they had left their homes without it. (Table IV).

\section{Discussion}

We identified a frequency of noncompliance of $41 \%$ in patients in whose the counting of medication could be carried out. This frequency was very high and evidenced that one of every two patients did not comply with prescribed therapy. Venter ${ }^{15}$ studied 68 African American patients and found a frequency of noncompliance of $65 \%$. Other authors report a frequency of noncompliance of 80 to $90 \%$, considering all the therapeutic measures. ${ }^{16}$

As for noncompliance with individual measures, the $62 \%$ dietary noncompliance found in this study was similar to the $73 \%$ reported by Watkins ${ }^{5}$, and to the $65 \%$ by Cerkoney. ${ }^{6}$ Diehl et a ${ }^{17}$ evaluated noncompliance in a similar way to our study, through the counting of pills and by measuring the quantity of insulin administered. They found frequencies of noncompliance between 40 and 50\%; Diehl's data are equivalent to the group of patients in our study in whom the counting of medication could be carried out and where the frequency of noncompliance was $41 \%$.

The frequency of noncompliance with exercise indications was $85 \%$ in our study. Through telephone 
Table II

Therapeutic compliance. MeXico City, I998-1999

\begin{tabular}{|c|c|c|c|c|c|c|}
\hline \multirow[b]{2}{*}{ Group } & \multicolumn{2}{|c|}{ Compliant } & \multicolumn{2}{|c|}{ Noncompliant } & \multicolumn{2}{|c|}{ Total } \\
\hline & $f$ & $\%$ & $f$ & $\%$ & $f$ & $\%$ \\
\hline Patients whose medication was counted* & 34 & 59 & 24 & 41 & 58 & 100 \\
\hline Patients treated only by diet or whose medication was not counted ${ }^{\ddagger}$ & 12 & 57 & 9 & 43 & 21 & 100 \\
\hline
\end{tabular}

* When counting of medication could be performed, a percentage of the number of missing pills or insulin units was obtained. In these patients counting of medication was considered $100 \%$ of their score

$\ddagger$ In patients whose medication could not be counted (because leftover medication was not kept or because they were only prescribed a specific diet), compliance with therapy components (diet, exercise, appointment keeping and medication) was measured by patients' own assessment of compliance. Compliance with dietary, exercise and medication indications was graded on a scale from zero to ten. The average score represented the final value of compliance. Patients were considered compliant when their score was $\geq 80 \%$

Table III

NONCOMPLIANCE WITH THERAPY COMPONENTS. MeXico City, 1998-1999

$$
\frac{\text { Non- }}{\text { Compliant }} \begin{gathered}
\text { compliant } \\
f \%
\end{gathered} \frac{\text { Total }}{f \%}
$$

Component

\begin{tabular}{lcccccc} 
Diet & 30 & 38 & 49 & 62 & 79 & 100 \\
\hline Exercise & 12 & 15 & 67 & 85 & 79 & 100 \\
\hline Hypoglycemic drugs, diet, and exercise & 44 & 83 & 9 & 17 & 53 & 100 \\
\hline Insulin, diet, and exercise & 14 & 88 & 2 & 12 & 16 & 100 \\
\hline Appointment keeping & 77 & 97 & 2 & 3 & 79 & 100
\end{tabular}

In patients whose medication could not be counted (because leftover medication was not kept or because they were only prescribed a specific diet), compliance with therapy components (diet, exercise, appointment keeping and medication) was measured by patients' own assessment of compliance. Compliance with dietary, exercise and medication indications was graded on a scale from zero to ten

When counting of medication could be performed, a percentage of the number of missing pills or insulin units was obtained. The other therapy components were evaluated with the same instrument as in patients whose medication could not be counted

calls, Kravitz et a $1^{18}$ studied the level of adherence to exercise, diet, and the administration of medication in patients with chronic diseases such as diabetes mellitus. They found frequencies of noncompliance of $19 \%$, $69 \%$, and $91 \%$ respectively. The frequency of noncompliance for appointment keeping was 3\% (2 patients), which indicates that even if patients do not miss their appointments, they still do not comply with the different therapeutic measures that are prescribed to them.

We evaluated the possibility that therapy noncompliance was related to some personal characteristics of the patient, sociodemographic characteristics, and disease characteristics, but no statistically significant associations were found. These results are consistent with

\section{Table IV}

REASONS FOR NONCOMPLIANCE WITH DIFFERENT THERAPY COMPONENTS (DIET, EXERCISE, INSULIN, AND hyPOGLYCEMIC DRUGS). MEXICO CITY, I998-1999

Variable f \%

Diet (33 patients)

Intrinsic to the person

$\begin{array}{lll}\text { Difficulty in changing dietetic habits* } & 29 & 87\end{array}$

Environmental causes

\begin{tabular}{lrr} 
Economic reasons & 10 & 30 \\
\hline Because of work or away from place of residence & 4 & 12 \\
\hline Difficulty to prepare it & 2 & 6 \\
\hline
\end{tabular}

Lack of instructions

Exercise (33 patients)

Intrinsic to the person

Related with idiosyncrasy motives and changes of habits ${ }^{\ddagger} \quad 9 \quad 27$

Environmental causes

Because they had no time or due to work $\quad 15 \quad 45$

Handicaps of the person

$\begin{array}{lll}\text { Due to a disease that did not allow them to carry it out }{ }^{\S} \quad 9 \quad 27 & 27\end{array}$

Hipoglycemic drugs (53 patients)

Intrinsic to the person

Related with idiosyncrasy motives and change of habits ${ }^{\#} \quad 1325$

Environmental causes

\begin{tabular}{lll} 
Economic reasons & I & 2 \\
\hline
\end{tabular}

Away from place of residence

Insulin (16 patients)

Intrinsic to the person

$\begin{array}{lll}\text { Because they forgot or because they felt fine } & 2 & 13\end{array}$

Environmental causes

\begin{tabular}{lrr} 
Economic motives & I r & 6 \\
\hline Away from home & 2 & 13 \\
\hline No person available to inject insulin & 1 & 6
\end{tabular}

* (They had cravings, they were hungry, the food was not what they were used to eating before, it did not seem necessary, etc.)

‡ (It is not important, they did not feel like it, they were not accustomed to it, they did not like it, etc.)

$\S$ Mainly arthritis

\# (They forgot, considered it useless, they did not buy them, they just missed taking them, etc.)

In this table, for reasons of noncompliant in diet and exercise we only included the noncompliance patients by counting medication $(n=33)$ 
those reported by other authors. ${ }^{15,16,18-20}$ The only significant association was the presence of systemic arterial hypertension and obesity in the presence of diabetes, especially the association with obesity already described ${ }^{21}$ It has been documented that overweight diabetic patients have more difficulty in their glycemic control. They have difficulties following dietary indications because they may have coexisting depressive symptoms and they have many problems to lose weight, even with strict diet programs.

In this study, a frequency of depression of $39 \%$ has been documented in a sample of patients with DM type-2 in Mexico City. This frequency is considerably high and it seems that in our society, most of the time, this problem is overlooked. The frequency of depression found in this study is higher in comparison to similar investigations, like the one of Bundo-Vidiella and collaborators, ${ }^{22}$ in which a group of 85 patients was studied, using the same scale as the one used in this study, and where the frequency of depression was $27 \%$. although the frequency was high, we could not found any association with noncompliance.

Among the reasons for noncompliance of the different therapeutic measures, two aspects of the diet were identified: one is related to the motivational aspect that involved $87 \%$ of the cases and the other is related to the environment (economical aspects, being away from home, and work activities) which involved $61 \%$. House et a ${ }^{23}$ found that the motivational causes accounted for $34 \%$ of noncompliance and those related to the environment, for $37 \%$. One group of somatic causes (blindness, physical restrictions) accounted for $26 \%$ for noncompliance. On the other hand, Schlundt ${ }^{24}$ found that out of 69 situations of diet noncompliance studied in 26 patients, 32 (46\%) were related to environmental reasons and $13(19 \%)$ to motivational aspects. In the two previous studies, economical difficulties for following dietary indications did not play an important role as in our population. Potential benefits of exercise in patients with DM2 have been documented, such as improvement in glycemic control, cardiovascular function, weight loss, positive psychological effects, and prevention of other diseases. ${ }^{25} \mathrm{Ka}$ miya carried out a survey among 570 diabetics to define the reasons of noncompliance with exercise; the two main reasons given were similar to the ones found in our study: "I have no time." and "I do not have that habit and I have no desire to exercise" ${ }^{26}$ These findings indicate that patients must be motivated in a proper way at the moment of diagnosis and throughout the evolution of the disease, in order to obtain the benefits of exercise.
Most of our patients with hypoglycemic drugs stopped taking them for intrinsic reasons (mainly forgetfulness) and because they were away from home; reasons that were similar to those of patients who were controlled with insulin. Our results are comparable to those from other studies in which the principal cause for noncompliance of medical measures was forgetfulness, as reported by Khoza et al. ${ }^{27}$

There are few studies that measure therapy compliance in the Mexican population. We recognize that our study is limited because the sample is not large. We consider that this problem should be analyzed in different contexts, populations, social levels, and social-economic strata, to gather a realistic panorama of the impact that it has on individual health and the public health importance of this problem.

\section{Acknowledgements}

The authors thank Silvia Armenta for helpful suggestions.

\section{References}

I. Martínez C, Guiscafré H, Muñoz O, Gutiérrez G. Análisis del incumplimiento del tratamiento con los esquemas terapéuticos utilizados. Arch Invest Med 1988;9:409-417.

2. Fletcher SW, Pappius EM, Harper SJ. Measurement of medication compliance in a clinical setting. Comparison of three methods in patients prescribed digoxina. Arch Intern Med 1979;139:635-638. 3. Rudd P. In search of the gold standard for compliance measurement. Arch Intern Med 1979;139:627-628.

4. Golin CE, DiMatteo MR, Gelberg L. The role of patient participation in the doctor visit. Diabetes Care 1996; 19:1154-I 164.

5. Watkins JD, Williams F, Martin DA, Hogan MD, Anderson E. A study of diabetic patients at home.J Am Public Health 1967;56:452-459.

6. Cerkoney $A B$, Hart K. The relationship between the health belief model and compliance of persons with diabetes mellitus. Diabetes Care 1980;3:594-598.

7. Morrison EY, Bennett F.Assessment of patient compliance in a diabetic clinic using glycated proteins compared with blood sugar measurements. West Indian Med J 1988;37:58-6I.

8. Irwin M, Rosenstock IM. Understanding and enhancing patient compliance with diabetic regimes. Diabetes Care 1985;8:610-616. 9. Nagasawa M, Smith MC, Barnes JH, Fincham JE. Meta-analysis of correlates of diabetes patients' compliance with prescribed medications. Diabetes Educ 1990;16:192-200.

10. Rull JA, Ríos JM, Gómez-Pérez FJ, Olaiz G, Tapia R, Sepúlveda J.The impact of diabetes mellitus on public health in Mexico. En: Schwartz C, Born G. New horizons in diabetes mellitus and cardiovascular disease. Curr Sci 1998;1:64-74.

II. Suárez-Mendoza A, Cardiel M, Caballero-Uribe C, Ortega-Soto H, Márquez-Marín M. Measurement of depression in Mexican patients with rheumatoid arthritis:Validity of the Beck Depression Inventory. J Rheumatol 1997;10:194-199. 
12. Torres-Castillo M, Hernández-Malpica E, Ortega-Soto HA.Validez y reproducibilidad del inventario para depresión de Beck en un hospital de cardiología. Salud Mental 1991;14:I-6.

13. Bronfman M, Guiscafré H, Castro V, Castro R, Gutiérrez G. La medición de la desigualdad: una estrategia metodológica, análisis de las características socioeconómicas de la muestra. Arch Invest Med 1988; 19:351-360.

14. Beck AT, Ward CH, Mendelsson A. An Inventory for measuring depression. Arch Gen Psychiatry 1961;4:561-57I.

15. Venter HL, Joubert PH, Foukaridis GN. Compliance in black patients with non-insulin-dependent diabetes mellitus receiving oral hypoglycaemic therapy. S Afr Med J 1991;79:549-55।.

16. Harris R, Linn M. Health beliefs, compliance, and control of diabetes mellitus. South Med J 1985;78:162-166.

17. Diehl AK, Bauer RL, Sugarek NJ. Correlates of medication compliance in non-insulin-dependent diabetes mellitus. South Med J 1987;80:332-335

18. Kravitz RL, Hays RD, Sherbourne CD, DiMatteo, Rogers WH, Ordway $L$ et al. Recall to recommendations and adherence to advice among patients with chronic medical conditions. Arch Intern Med 1993; 16: 1869-1878.

19. Pringle M, Stewart-Evans C, Coupland C, Williams I, Allison S, Sterland J. Influences on control in diabetes mellitus: Patient, doctor, practice or delivery of care? Br Med J 1993;306:630-634.
20. O'Connor PJ, Fragneto R, Coulehan J, Crabtree BF. Metabolic control in non-insulin-dependent diabetes mellitus: Factors associated with patient outcomes. Diabetes Care 1987; 10: 697-701.

21.Wing RR, Epstein LH, Nowalk MP, Scott N, Koeske R, Hagg S. Does self-monitoring of blood glucose levels improve dietary compliance for obese patients with type II diabetes? Am J Med 1986;8I:830-836. 22. Bundo-Vidiella M, Auba-Llambrich J, Massons-Cirera J, Trilla-Soler MC, Pérez-Villegas R, Pérez-del Campo AM. Ansiedad y depresión en pacientes diabéticos tipo II. Aten Primaria 1996;17:58-62.

23. House W, Pendleton L, Parker L. Patients' Versus physicians' attributions of reasons for diabetic patients' noncompliance with diet. Diabetes Care 1986;9:434.

24. Schlundt DG, Rea MR, Kline S, Pichert JW. Situational obstacles to dietary adherence for adults with diabetes. J Am Diet Assoc 1994;8:874879.

25. Schneider SH, Johnson RW, Ruderman NB. Exercise and DIDDM. Diabetes Care 1990;13:785-789.

26. Kamiya A, Osawa I, Fujii T, Nagai M, Yamanouchi K, Oshida Y et al.A clinical survey of the compliance of exercise therapy for diabetic outpatients. Diabetes Res Clin Pract 1995;27: 141-145.

27. Khoza SR, Kortenbout W. An investigation of compliance in type II diabetic patients attending clinic at Church of Scotland Hospital. Curationis 1995;18:10-14. 